\title{
Pistas metodológicas para sistematizar las acciones colectivas en el marco del paro nacional en abril-junio de 2021 en Cali, Colombia
}

Methodological clues to systematize collective actions in the framework of the National Strike in April-June 2021 in Cali, Colombia

Pistas metodológicas para sistematizar ações coletivas no marco da Greve Nacional em abril-junho de 2021 em Cali, Colômbia

Lorena MARÍN GUTIÉRREZ

Universidad del Valle (Colombia)

lorena.marin@correounivalle.edu.co

Chasqui. Revista Latinoamericana de Comunicación

N.o 148, diciembre 2021 - marzo 2022 (Sección Monográfico, pp. 195-216)

ISSN 1390-1079 / e-ISSN 1390-924X

Ecuador: CIESPAL

Recibido:30-06-2021 / Aprobado: 12-11-2021 


\title{
Resumen
}

Este artículo pretende brindar pistas metodológicas para abordar la complejidad del accionar colectivo en el marco del reciente paro nacional de Colombia, que inició el pasado 28 de abril de 2021, a la luz de una apuesta de sistematización de experiencias denominada "la espectrónica" (espectro de acción colectiva). En este ensayo se esboza un panorama de la actual coyuntura de paro nacional con énfasis en la ciudad de Cali, y posteriormente se adentra en el concepto de acción colectiva a partir de la perspectiva metodológica de la espectrónica para potenciar la gestión colectiva del conocimiento que nace desde estas prácticas asociativas.

Palabras clave: acción colectiva, sistematización de experiencias, educación popular, conocimiento emancipatorio.

\begin{abstract}
This article intends to offer methodological hints to tackle the complexity of collective action that has taken place in the context of the current National Strike in Colombia, which began on april 28, 2021, in the light of an experience systematization proposal called "the spectronic" (spectrum of collective action). In this essay there will be an overview of the National Strike with an emphasis on what has happened in the city of Cali, followed by the discussion of the concept of collective action from the methodological perspective of "the spectronic", to try to strengthen the collective understanding born from these associative practices.
\end{abstract}

Keywords: collective action, experience systematization, popular education, emancipatory knowledge.

\section{Resumo}

$\mathrm{O}$ artigo procura oferecer pistas metodológicas para abordar a complexidade do atuar coletivo no marco do recente paro nacional da Colômbia, iniciado o passado 28 de abril do 2021, na luz de uma proposta de sistematização de experiências chamada "a espectrônica" (espectro de ação coletiva). Neste ensaio esboça-se um panorama da atual conjuntura do paro nacional, e depois aprofunda no conceito de "ação coletiva" a partir da perspectiva metodológica da espectrônica para potenciar a gestão coletiva do conhecimento que nasce desde estas práticas associativas.

Palavras-chave: ação coletiva, sistematização de experiências, educação popular, conhecimento emancipatório. 


\section{Introducción}

Desde finales de abril de 2021, en la ciudad de Cali, hemos asistido a una serie de transformaciones correspondientes al paro nacional convocado el 28 de abril. El contexto de pandemia con sus correspondientes políticas de salud pública, empujaron a una buena parte de la sociedad caleña a la pobreza, en una ciudad que ya venía abonando durante décadas una enorme crisis social, intensificada por el recrudecimiento de la guerra y el narcotráfico. El anuncio de la reforma tributaria por parte del presidente Iván Duque encendió la chispa y se convocaron varias protestas en distintos puntos de la ciudad que de alguna manera daban continuidad a las movilizaciones que tuvieron lugar en noviembre de 2019 (21N). Aunque la reforma tributaria fue el detonante, las razones para protestar se venían acumulando: la ya mencionada precarización por el mal manejo de la pandemia, constantes asesinatos de líderes sociales sin respuesta eficaz por parte del gobierno, la corrupción, entre otros factores agravantes.

Cali se convirtió en el epicentro de esta protesta social, tanto por lo masivo de las manifestaciones y puntos de resistencia, como por la violenta represión y la nula voluntad de diálogo por parte del Estado. Esto ha volcado a numerosos colectivos, organizaciones sociales, entre otros, a intentar comprender las particularidades de estos eventos que podemos ver como expresiones del subsuelo (Tapia, 2001). Al mismo tiempo, esta coyuntura febril ha visto nacer formas variadas de acción colectiva ${ }^{1}$ que orbitan alrededor de las demandas y necesidades del paro. Dichas dinámicas están atravesadas por la solidaridad y la empatía en medio de una polarización muy marcada que deslegitima la protesta, poniendo a disposición saberes, medios y herramientas para potenciar, visibilizar, entender y proyectar las fuerzas que atraviesan estos procesos de transformación.

Es en este sentido que se presenta una propuesta para sistematizar acciones colectivas que nació en el año 2011 en Cali y que podría ser útil para pensar las diversas y complejas dinámicas asociativas que han tenido lugar entre finales del mes de abril y junio de 2021 en esta ciudad. La espectrónica nació como un ejercicio informal de levantamiento y análisis de acciones colectivas que, a la luz de una investigación académica, fue potenciada como un modo particular de sistematización de acciones colectivas desde la educación popular. Las perspectivas metodológicas que se brindan en este documento no corresponden a un modelo estructural que brinda un marco explicativo y definitivo de las acciones colectivas. Se presenta esa iniciativa de investigación informal enriquecida desde el modelo de sistematización de experiencias trabajado por el Grupo de Investigación en Educación Popular de la Universidad del Valle, y

1 Si bien una de las modalidades de acción colectiva, la acción colectiva contenciosa, es "el bloqueo simultáneo y sostenido de una serie de cruces viales que fueron rápidamente convertidos en una red de nodos de resistencia barrial" (Hernández, 2021, p. 138), en este caso me refiero a otro tipo de acción colectiva cuyas características desarrollo en los apartados 2 y 3 de este documento. 
también alimentada a partir de los aportes analíticos de Torres (2011) y Barragán y Torres (2018).

Debido a la proximidad temporal con el paro, este documento se presenta como un acercamiento preliminar y exploratorio. Los elementos aquí consignados obedecen a la participación activa de la autora en algunas de las actividades convocadas por distintos puntos de concentración, a la revisión del archivo (digital) en marcha de la coyuntura del Paro en Cali y a conversaciones con distintas personas y colectivos que hacen presencia en estos espacios. Sin embargo, no se plantea a la manera de un estudio de caso sino como una propuesta a ser apropiada por distintos sectores para hacer legibles las fuerzas que mueven a las personas a juntarse y generar propuestas que, desde la cotidianidad, producen significativos horizontes de transformación.

Este ensayo se desarrollará en cuatro apartados: En primer lugar (1) me propongo brindar un contexto sobre el paro nacional, abordando algunas particularidades de Cali y las estrategias de borradura que se han implementado. Posteriormente (2), me aproximo a la noción de acción colectiva desde un recorrido histórico para luego enfatizar en los elementos analíticos más significativos para esta propuesta. En el siguiente apartado (3), presento a la espectrónica como una apuesta metodológica con una perspectiva emancipatoria desde la que se pueden leer y potenciar las acciones colectivas. Finalmente (4) se presentan algunos comentarios de cierre sobre la producción de conocimiento emancipatorio en tiempos de necropolítica.

\section{Cali, epicentro del paro nacional 2o21: entre resistencias y borraduras}

El paro nacional iniciado el 28 de abril de 2021 es considerado el estallido social más amplio y masivo que ha tenido Colombia en su historia (Castillo, 2021, p. 99), cuyas causas y particularidades deben comprenderse en una temporalidad amplia de décadas de cultivo de una gran desigualdad, conflicto interno y políticas neoliberales que han acumulado diversas formas de violencia y exclusión. Además de esto, el incumplimiento del Acuerdo de Paz, firmado en noviembre de 2016, y la alarmante cifra de más de 1100 líderes sociales asesinado ${ }^{2}$ desde ese año, han generado un clima de indignación y desconfianza institucional.

Cali es una de las ciudades más grandes de Colombia cuya densidad poblacional y posición geopolítica la ubican como un lugar central en el suroccidente del país. Sus dinámicas de poblamiento urbano se han nutrido desde los años cuarenta y a lo largo de varias décadas a partir de oleadas de

2 Indepaz (Instituto de estudios para el Desarrollo y la Paz) publicó un informe actualizado el 22 de abril de 2021 identificando 1166 líderes y defensores de derechos humanos asesinados, de los cuales 768 ocurrieron durante el gobierno del actual. Ver http://www.indepaz.org.co/con-lideres-hay-paz-agresiones-contra-la-paz-en-colombia/ 
migraciones y desplazamientos forzados provenientes de la zona cafetera, el suroccidente y, sobretodo, el pacífico colombiano, lo cual ha contribuido a la alta densidad de población afrodescendiente:

Cientos de familias, a veces poblados, veredas y corregimientos enteros llegaron a través de la activación de sus redes familiares y de paisanos a la ladera de Cali, a las comunas 18 y 20, y al oriente, en lo que luego se conocería como el distrito de Aguablanca, para formar las comunas 13, 14, 15, 16, y 21. (Salazar, 2021, p. 153)

Estas complejas dinámicas migratorias han generado una marcada segregación urbana, racial y económica. Además, la ciudad está atravesada, desde los años ochenta hasta el presente, por el fenómeno del narcotráfico, lo cual ha influido enormemente en sus dinámicas culturales, políticas y económicas, y ha contribuido a convertirla en una de las ciudades más violentas del país.

Desde la revuelta de los Comuneros ${ }^{3}$ en el siglo XVIII, y el Paro Cívico de 1977 (considerado como el más grande y violento hasta el momento) ${ }^{4}$ no se había visto un levantamiento popular de tal magnitud vinculado a una reforma tributaria. Sin embargo, reducir las causas del paro a una reforma tributaria es desconocer el cansancio de décadas de desigualdad, violencia y corrupción, que condujeron a una "olla de presión pronta a estallar en cualquier momento" (Castillo, 2021, p. 100). Por otra parte, Cruz (2016) identifica un ciclo ascendente de protestas de grandes magnitudes en Colombia entre los años 2010 y 2016 cuyo comportamiento y transformación debe tener en cuenta:

el contexto político en el que tiene lugar el ciclo de protesta se caracteriza por un cierre relativo de la arena política institucional, que incentiva formas de tramitar demandas sociales alternativas a la política representativa, como la protesta social. Al mismo tiempo, la represión y las consecuencias adversas del conflicto armado sobre las organizaciones y la protesta social se mantienen como una constante que impone altos costos a la acción colectiva. No obstante, las movilizaciones han sido posibles porque, por una parte, existe una recomposición organizativa y discursiva en los movimientos sociales, necesaria para agenciar acciones colectivas de grandes magnitudes y articular diversos actores [...]. (Cruz. 2016, p. 35)

En este documento podemos comprender la antesala de la protesta social de los años $2019(21 \mathrm{~N})$ y 2021, año en el que la pandemia recrudece la crisis social, económica y de legitimidad del actual gobierno. En este último caso, la dinámica de desigualdad y segregación marcó una importante característica del

3 La revuelta de los Comuneros (1781) fue una insurrección popular desencadenada por un alza de impuestos del poder colonial del Virreinato (Arciniegas, 1939).

4 El Paro Cívico de 1977 ocurrió en el mandato de López Michelsen (1974-1978). Fue convocado por sindicatos, pero se adhirieron "campesinos, liderados por la Anuc, y varios sectores urbanos - pobladores barriales, estudiantes, jóvenes, amas de casa, desempleados, vendedores ambulantes” (García, 2017, p.19). 
paro nacional en la ciudad de Cali. Por su parte, Hernández (2021) esgrime en la hipótesis de su artículo que:

en Cali hubo una especie de levantamiento popular urbano, protagonizado especialmente por jóvenes de los barrios de estratos bajos, que se cobijaron bajo la sombrilla del paro nacional para poner de presente sus propias demandas de reconocimiento social y oportunidades de vida digna digna, más que mera inclusión al orden establecido, mediante formas de acción novedosas y eficaces, por motivos diferenciados pero complementarios de los del comité nacional de paro y sus aliados. (Hernández, 2021, p. 127-128)

Este mismo autor plantea que tanto en este paro como en las jornadas de protesta del 2019, hubo una "explosión generalizada de ira popular" (Hernández, 2021, p. 130) después de una seguidilla de actos de brutalidad policial. ${ }^{5}$ Todo esto genera una convocatoria masiva para el $28 \mathrm{~A}$, pero a diferencia del $21 \mathrm{~N}$ de 2019, en la ciudad de Cali se convocaron varios puntos de resistencia y no una gran marcha hacia el centro administrativo, como se hacía anteriormente. El día arrancó con un acto de resignificación histórica de los símbolos de la mano del derrumbamiento de la estatua del conquistador Sebastián de Belalcázar por parte del pueblo indígena Misak. Este acto ha sido leído como parte de un proceso más amplio de desestabilización de "monumentos que ayudaban a sostener el sentido común” (Díaz, 2021, p. 632).

Ilustración 1. Estatua de Sebastián de Belalcázar derribada el 28 de abril de 2021. Cali, Colombia

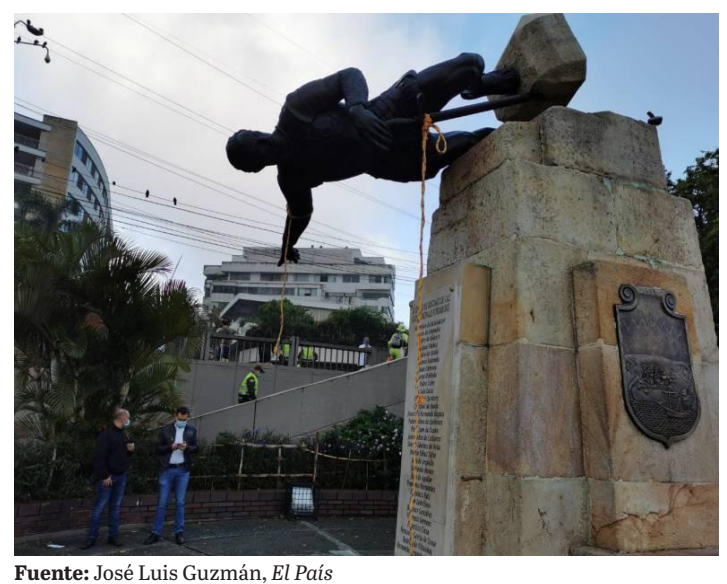

Fuente: José Luis Guzmán, El País

5 Cuestión Pública identificó que, en Colombia, entre 2019 y el 20 de mayo de 2021, 56 personas murieron en medio de las movilizaciones sociales, de las cuales 48 murieron entre el 28 de abril y el 20 de mayo de 2021. Recuperado de https://cuestionpublica.com/en-memoria-victimas-mortales-abuso-policial-violencia-movilizaciones-sociales/ El 28 de junio, Indepaz publicó una nueva lista identificando 74 muertes por violencia homicida desde inicios del Paro. 
Los puntos de concentración se nutrieron masivamente, ocasionando un colapso en la movilidad. Se ubicaron en las avenidas que conectan a la ciudad con sus vecinas, en las autopistas que acentúan la división en laderas, distrito de Aguablanca y centro (la ciudad formal), haciendo más visible la segregación.

Ilustración 2. Puntos de concentración paro nacional en Cali

\section{Puntos de Concentración en el Marco del Paro Nacional en Cali}

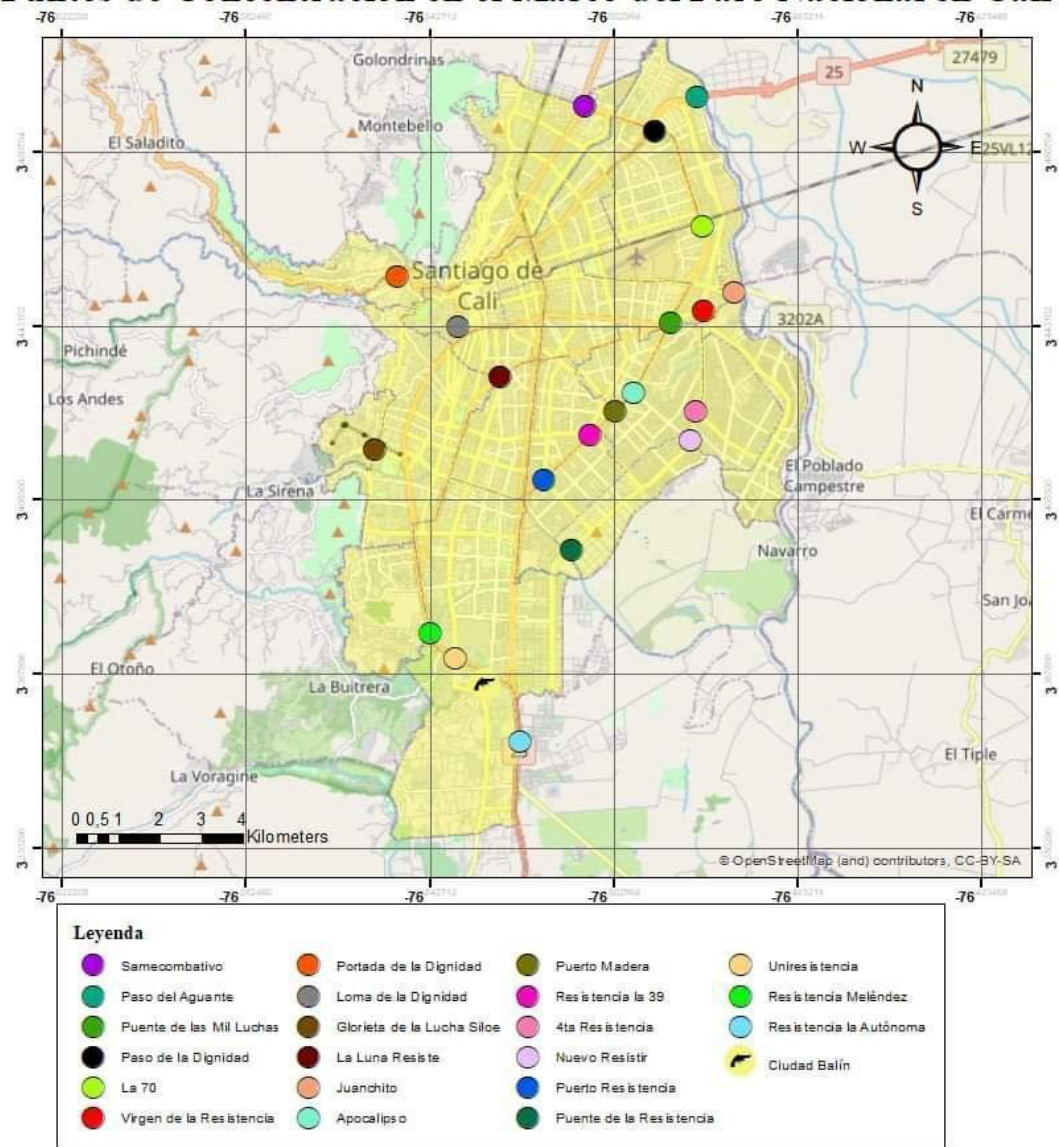

$\begin{array}{llc}\text { Información Cartográfica: } & \text { Información Temática: } & \text { Escala: } 1: 120.000 \\ \text { Open Street Map } & \text { Información recogida } & \text { MAGNA Cali, Valle 2009 } \\ \text { IDESC Cali } & \text { en Campo } & \text { Año: 2021 }\end{array}$

f Tejiendo Territorios (0) @tejiendo.territorios

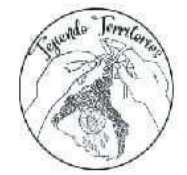

Fuente: Tejiendo territorios, 2 de junio de 2021 
Pronto los puntos de concentración se fueron tornando permanentes. En su balance sobre la acción colectiva contenciosa, abordada como uno de los aspectos novedosos de este paro nacional en la ciudad de Cali, Hernández (2021) plantea que:

El bloqueo simultáneo y sostenido en el tiempo de una constelación de puntos de resistencia, en una misma ciudad, mecanismo que garantiza de manera significativa la parálisis del trabajo y la producción, protege a los activistas de la represión al permitirles actuar cerca de los barrios a los que pertenecen, territorializa las luchas sociales urbanas por sectores, resignifica y reinventa la ciudad al cambiar nombres de lugares emblemáticos, convierte instalaciones policiales en centros culturales, funda nuevas plazas públicas y puebla con nuevas gestas la memoria colectiva de los ciudadanos. (Hernández, 2021, p. 147-148)

Se trata entonces de un fenómeno de descentralización de la lucha social, siendo las bases las que gestaron sus proyectos movilizadores en sus territorios y no una entidad central como el Comité Nacional del Paro, pues "no se trató de un paro de la producción, sino de una revuelta popular que acudió a la barricada y al bloqueo de calles para expresar su indignación ante el actual estado de cosas y cuestionó los espacios de la dominación urbana, retardando la circulación y la "realización" del capital" (Libreros, 2021, p.16).

Mientras estos puntos ganan fuerza y pronto se constituyen en la Unión de Resistencias de Cali (URC), desde afuera (medios de comunicación hegemónicos) se alimenta una lectura de que lo que allí ocurre son focos de delincuencia, narcotráfico, disidencia de guerrillas y otras fuerzas "oscuras". Aunque no se puede desconocer la complejidad de actores reunidos en los puntos, derivada de las dinámicas de desigualdad fraguadas durante décadas en la ciudad, ${ }^{6}$ la poca credibilidad adjudicada al poder popular genera sospechas. La narrativa sesgada de los noticieros locales planteó que una vez se tumbó la reforma tributaria, no había más razones para continuar (continuar sería un capricho vandálico o un plan macabro para desestabilizar el país). Por lo tanto, el gobierno nacional ordenó el máximo despliegue militar, interrumpiendo los torpes intentos de la administración local para generar diálogo. La idea era clara: garantizar el retorno a la normalidad.

Si seguimos la lógica de quienes defienden un estatus quo y buscan restituir la "normalidad", se revela la superficie en la que, desde la perspectiva de Tapia (2001), se hace visible la "topografía de las instituciones que ordenan la vida social” (Tapia, 2001, p. 95). En esta superficie se erigen los discursos y prácticas de una ciudad deseable, que, al mirar desde una perspectiva histórica oficial,

6 Otro de los elementos significativos de Hernández es su perspectiva de los ciclos de violencia: se presenta la violencia represiva por parte del ESMAD (Escuadrón Móvil Anti Disturbios), la violencia colectiva defensiva por parte de los manifestantes, también se presenta la violencia oportunista que involucra cobro de peajes, saqueos a almacenes y a estaciones de gasolina, y la violencia vengativa por parte de civiles armados que se toma la justicia por mano propia para garantizar el control de la ciudad (Hernández, 2021). 
revelan los vestigios del discurso del civismo y del amor por Cali. Esta versión de la ciudadanía deseable se conecta hoy en día con la llamada "ciudadanía de bien"7 y que ha esgrimido consignas polarizantes como "los buenos somos más". Lo que a este sector le molesta es precisamente la fisura del subsuelo que ha vuelto ruidoso e insoportable lo que antes del Paro yacía invisible e inaudible.

Algunos de los argumentos y acciones que denuncian son la irrupción de actos vandálicos por parte de los manifestantes, la destrucción de bienes públicos y la amenaza a la propiedad privada, además de la incomodidad de los bloqueos que para ellos representan un "secuestro" y limitación a la libertad de movimiento. Estas razones fueron generando el caldo de cultivo de un fenómeno de violencia denominada como "vengativa" por Hernández (2021), que tuvo varias expresiones. En particular, el 9 y el 28 de mayo se presentaron dos de estos hechos en uno de los barrios de estrato alto de Cali llamado Ciudad Jardín, en los que se expresó la actuación mancomunada entre la fuerza pública y civiles armados contra la minga indígena (el 9 de mayo ${ }^{8}$ y contra los manifestantes (el 28 de mayo). ${ }^{9}$ El colectivo periodismo de investigación Cuestión Pública, publicó dos especiales sobre estas fechas relevantes y planteó que estos eventos contaron con la participación del congresista del Centro Democrático (partido de derecha) Christian Garcés.

Es importante visibilizar el arraigo de la lógica contrainsurgente en las dinámicas sociales en Colombia que Cruz (2015) menciona como un efecto del conflicto armado en el marco de la matriz política con la que desde la Guerra Fría se consolidó el enfrentamiento del "enemigo interno" y que ha afectado a la protesta social al reducir "las oportunidades para la organización y la acción colectiva, al vulnerar los derechos de asociación, reunión y expresión” (Cruz, 2015, p. 54). Esto también pone en el centro la articulación entre "actores públicos y privados, legales e ilegales" que buscan reprimir dichas amenazas. Estos actores se ubican entre los sectores militares, élites locales y narcotraficantes mancomunados con grupos paramilitares, tal como sucedió en la represión a toda iniciativa considerada de izquierda en los años ochenta, bajo el mandato de Belisario Betancur (1982-1986) (Cruz, 2015, p. 56).

A pesar de que se revelaron los nexos entre dirigentes políticos, una parte de la élite de la ciudad y grupos de civiles de actuación paramilitar, no ha habido ninguna judicialización de estos hechos. Esta impunidad dice mucho sobre la primacía y naturalización de un tipo de visión de mundo que implica la invisibilización de la profunda desigualdad que la sostiene. En otras palabras, el privilegio del que goza la población de clases acomodadas es dado por sentado,

7 La ciudadanía de bien es un término acuñado para designar una parte de la población urbana que se identifica con valores hegemónicos asociados a comportamientos deseables y funcionales al buen funcionamiento del Estado y que se contrapone a quienes pretenden desestabilizar las lógicas establecidas.

8 Ver Cuestión Pública https://cuestionpublica.com/paso-a-paso-asi-fue-el-tiroteo-del-9-de-mayo-alsur-de-cali/

9 Ver Cuestión Pública https://cuestionpublica.com/cuando-la-policia-se-alio-con-hombres-armadosvestidos-de-civil/ 
y esto a sus ojos justifica acallar, a toda costa, las manifestaciones de aquellos que no tienen acceso a oportunidades, puesto que esta visión de privilegio se sostiene sobre la ficción meritocrática de que todos somos iguales, de que todos partimos del mismo lugar y con las mismas condiciones, y que esa condición de privilegio es fácilmente accesible a todos si así se lo proponen.

La filósofa Marina Garcés (2020) identifica dos ficciones que sostienen la idea del "poder ser" (que podemos entender como la posibilidad de acceder a educación, empleo y otros derechos garantizados por la Constitución). La primera es la "ficción jurídica de igualdad de oportunidades", una idea liberal que plantea que todos partimos del mismo lugar y jugamos en un campo neutro. La segunda es la "ficción extractivista de la idea de potencial", una idea neoliberal que plantea al individuo como un sujeto lleno de potencial, presto para sacarle el máximo provecho (Garcés, 2020, p. 51). Estas dos ideas fomentan una lectura de la meritocracia individualista en igualdad de condiciones que deja por fuera la lógica excluyente sobre la que opera.

Sin embargo, lo que se deriva de estas dos ficciones es la producción de seres residuales que no pueden ni siquiera acceder a lo que se supone está garantizado constitucionalmente. Podemos decir que estas vidas residuales han encontrado en el subsuelo del Paro un horizonte emancipatorio para luchar por el reconocimiento y por condiciones de vida dignas. Así que las grietas que producen en la superficie pueden ser leídas desde abajo como la manifestación diversa de la resistencia, pero desde arriba siguen teniendo la impronta de lo indeseable que en ese sentido puede (debe) ser borrado.

Desde los múltiples murales y grafitis, hasta la quema de buses y estaciones del sistema masivo de transportes MIO, el daño de infraestructura pública que produce escombros y la construcción de barricadas hacen parte de un paisaje que confronta la forma urbana, la contradice y tensiona, también la completa en sus narrativas subalternas (Márquez, 2020, p. 3). Tal como en el caso chileno, en Cali se han realizado varias prácticas de borradura y asepsia que pretenden retomar el cauce de la normalidad. Los muros y calles se han llenado de mensajes que denuncian el mundo de injusticias y anuncian otras posibilidades. Debido a las dinámicas de brutalidad policial, una de las prácticas artísticas más recurrentes ha sido la visibilización de rostros de las víctimas. Con ese gesto viene la borradura institucional. En Bogotá sucedió en septiembre de 2020. Como se puede observar en la Ilustración 3, la policía da los primeros brochazos de pintura en el rostro de Julieth Ramírez, joven asesinada el 9 de septiembre junto a otras 13 personas. 
Ilustración 3. Mural de Julieth Ramírez borrado por la policía nacional, 13 de septiembre de 2020

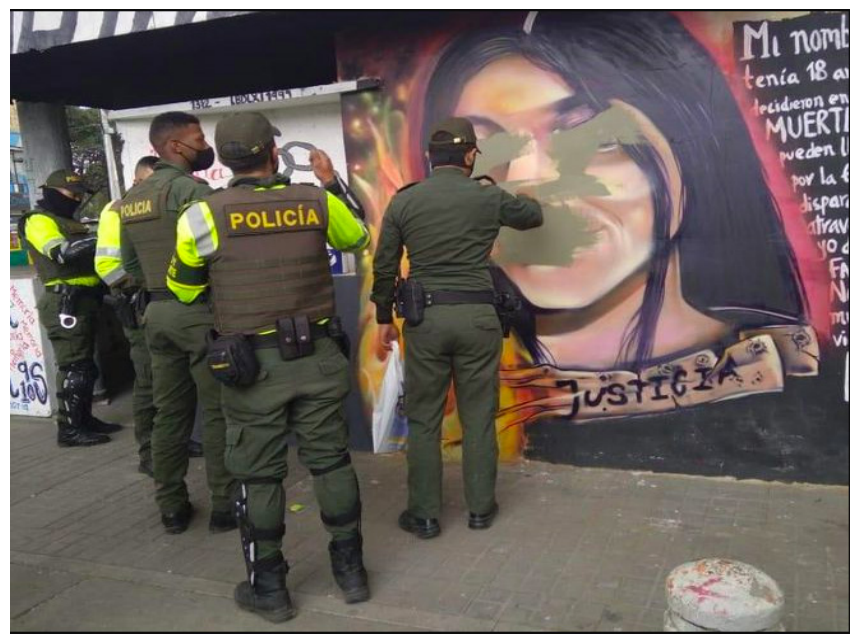

Fuente: El espectador

En Cali también se han borrado varios murales; en la Ilustración 4, en la foto de arriba se puede ver un mensaje que anuncia: "En Cali secuestran mujeres", pintado previamente al Paro como una gran denuncia ante los alarmantes casos que se presentaron en los meses anteriores. Más abajo dice "paren el genocidio". En la imagen de abajo, se puede ver cómo en el marco del Paro se activa la máquina de borradura.

Ilustración 4. Murales en Cali, Colombia, 17 de junio
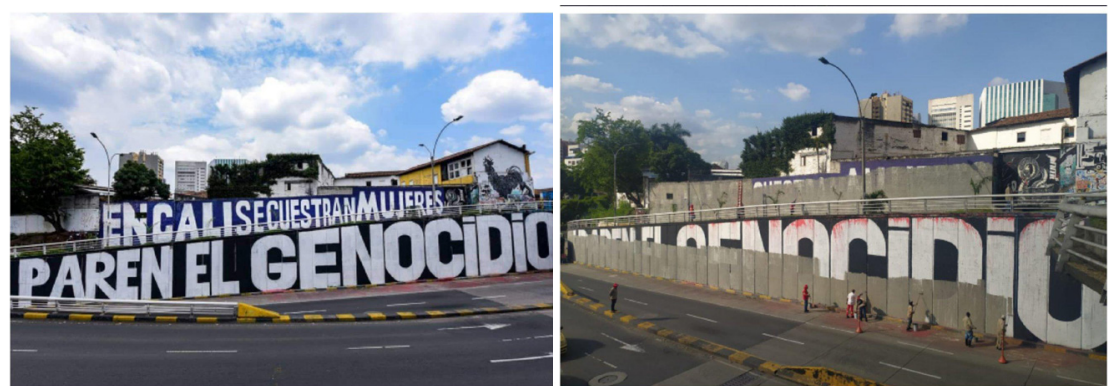

Fuente: Twitter Mayte Misas Tique

Otra borradura que se ha intentado ejecutar, hasta el momento infructuosamente, es la del Monumento a la Resistencia, inaugurado el 13 de junio de 2021 en Puerto Resistencia fruto de una dinámica asociativa. Este monumento se erige con un brazo que sostiene un cartel que dice "resiste", y 
está cubierto por varios grafitis y los escudos con los rostros de las víctimas de la primera línea.

Ilustración 5 y 6. Monumento a la Resistencia, 13 de junio de 2021. Puerto Resistencia Cali, Colombia

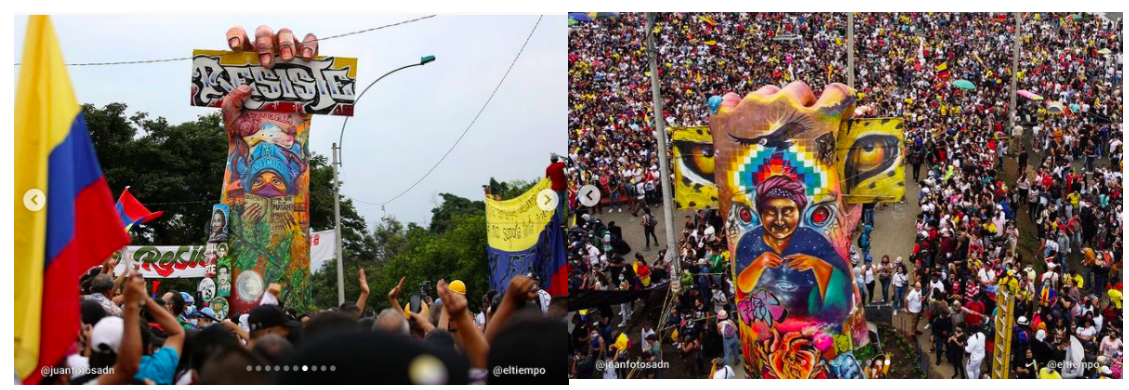

Fuente: @juanfotosadn

También se han visto otro tipo de borraduras que no ocurren sobre la infraestructura sino sobre los cuerpos. Desde el nacimiento de los distintos puntos de resistencia se han venido presentando atentados por parte de civiles armados en carros polarizados. Esta noticia ha hecho parte del paisaje desde los primeros días del Paro. Las lógicas de muerte configuran lo que se conoce como necropolítica (Mbembe, 2020): cuerpos que aparecen flotando en los ríos de la ciudad, cuerpos calcinados con signos de tortura, ${ }^{10}$ cuerpos desmembrados que aparecen en zonas abandonadas o en espacios como caños de aguas residuales. ${ }^{11}$ Se trata de homicidios ejemplarizantes que advierten que el precio a pagar por la osadía de la protesta es muy alto.

En su artículo centrado en el Pacífico sur colombiano, Pazos-Cárdenas (2021) recoge los conceptos de necropolítica y capitalismo gore para dar cuenta de las dinámicas de violencia que allí operan. Identifica y caracteriza las figuras de "necro-poder" o "necro-empoderamiento" "para referirse al proceso mediante el cual las formas de violencia y muerte se desligan de la exclusividad de lo aparatos militares y estatales y pasan a ser ejercidas por estos "sujetos

10 Se trata del caso de Daniel Stiven Sánchez, cuyo cuerpo calcinado fue encontrado sin vida el 28 de mayo en un local comercial que fue incendiado. Pese a que testigos aseguran que el ESMAD lo golpeó brutalmente y lo subió a una tanqueta, la necropsia aseguró no encontrar signos de tortura. La familia de Daniel se encuentra amenazada. Ver más información en https://www.justiciaypazcolombia.com/en-riesgo-de-atentado-y-desplazamiento-forzado-se-encuentran-los-familiares-del-menor-daniel-stiven-sanchez-encontrado-sin-vida-en-el-dollacity-de-siloe-como-resultado-de-la-represion-policial-del-28/

11 Si bien se hace difícil relacionar el descubrimiento de cuerpos hallados en los últimos meses con los desaparecidos del paro nacional, el video que circuló de un policía diciendole en una zona rural del Valle del Cauca a una persona "ya cogimos a un amigo tuyo, andá a buscarlo al río" revela la lógica macabra de los cuerpos que desde los ochenta han flotado en el río producto en su mayoría de la violencia paramilitar. Ver más información en https://www.elespectador.com/colombia-20/analistas/anda-a-buscarlo-al-rio-article/ 
endriagos", que incurren en prácticas de muerte para conseguir, y mantener poder y autoafirmación sobre los territorios y la vida misma de las personas que los habitan" (Pazos-Cárdenas, 2021, p. 5-6).

Precisamente esta espectacularización de la violencia se puede entender como una pedagogía del silenciamiento o borradura de estas resistencias, afín con lo que Segato (2018) menciona como pedagogías de la crueldad, considerando que:

El mundo de dueños que habitamos necesita de personalidades no empáticas, de sujetos incapaces de experimentar la conmutabilidad de las posiciones, es decir, de ponerse en el lugar de lo otro. No se trata simplemente de violencia, sino de un tipo de violencia muy particular por la cual la victoria, la aniquilación, no resulta de una muerte humana sino de la sustracción de la humanidad de lo aniquilado. (Segato, 2018, 81)

Por su parte, Quintana (2020) advierte que en las dinámicas neoliberales en las que se inscriben las economías de precarización, se producen formas de desposesión de los cuerpos de "su relacionalidad, de su movilidad, de su potencia común para actuar con otros, inhibiendo los deseos por otras formas de vida, los afectos transformativos que llevan a los cuerpos a alterarse" (Quintana, 2020, p. 51). Ella también asocia esto a una actitud "inmunitaria, afectiva y a la vez enjuiciadora que cierra a los cuerpos a la contingencia y a su relacionalidad, aunque no de manera inevitable" (p. 45).

Justamente, por su carácter contingente y potencialmente reversible es necesario fijarnos en las posibilidades de romper con esa desposesión de los cuerpos, y percibir las fuerzas colectivas que han seguido insistiendo en la configuración de tejidos y formas asociativas que merecen una especial atención. A continuación, se presenta el panorama conceptual que nutre la perspectiva de acción colectiva de la espectrónica.

\section{Acciones colectivas}

Las acciones colectivas han sido analizadas ampliamente desde el terreno de la ciencia política y la sociología orbitando el estudio de los movimientos sociales, pero en los últimos años han ido ganando terreno en las ciencias sociales desde enfoques diversos y desde la educación popular.

Desde las ciencias sociales, Delgado (2007) se concentra en los enfoques constructivistas a partir de los nuevos movimientos sociales (NMS) que buscan dar cuenta de algunas formas de acción de la segunda mitad de los años sesenta que se salían de los marcos existentes hasta el momento. En esta perspectiva la dimensión identitaria se sitúa en el centro del análisis (Delgado, 2007, p. 43).

Por otra parte, menciona la centralidad del aporte de Melucci (1994) a los movimientos sociales como agentes productores de significados colectiva con tres aspectos: 
1) que los movimientos sociales apelan a la solidaridad entendida como la capacidad de sus miembros para definir y reconocer un sentido del nosotros, y desde ahí compartir y construir una identidad colectiva como producto del proceso de atribución de significado y de las cambiantes situaciones que motivan la acción colectiva; 2) que la movilización explicita un conflicto social en la medida en que los miembros perciben una condición problemática o un aspecto de sus vidas no simplemente como una desgracia, sino como una injusticia, configurando paulatinamente un marco de interpretación compartido desde donde justifican y legitiman su acción colectiva; 3) que la acción busca romper los límites del orden en que se produce, por lo cual se considera básica la capacidad del movimiento para provocar rupturas en las fronteras del poder en el que se desarrolla su acción política; el propósito es diferenciar los movimientos de otros fenómenos que no tienen la intención de producir cambios en dicho sistema de normas y relaciones sociales. (Delgado, 2007, p. 45)

Desde una perspectiva nacional, Cruz (2014) plantea que la explicación integral de la acción colectiva debería tener en cuenta las dimensiones: estructural (Estructura de Oportunidad Política, desde la cual se interpretan ciertos contextos como favorables para la protesta), la organización (estructuras de organización, que evidencian las recomposiciones organizativas que tienen la capacidad de movilizar) y la dimensión subjetiva (marcos de acción colectiva, desde los cuales se interpreta el mundo). Esta última dimensión implica “identificar: 1) el diagnóstico de la realidad, por qué las cosas no son como deberían ser y quiénes son los responsables, el antagonismo; 2) la identidad, o la autodefinición de un 'nosotros' a partir de articulaciones, que están de acuerdo con 3) una solución a los problemas, un deber ser en función del cual se produce la acción colectiva" (Cruz, 2014, p. 271). Estos aspectos han sido abordados por Castillo (2021) en la coyuntura del paro nacional iniciado el 28A quien asegura que

La teoría de los movimientos sociales y la acción colectiva enseña que en las sociedades contemporáneas siempre habrá razones para que la gente proteste y se movilice, pero el tránsito de estos estados latentes a una convulsión social, como la que vive Colombia y Cali, implica la mezcla compleja de causas estructurales y coyunturales y de condiciones de oportunidad política que conectan recursos, organizaciones e identidades colectivas. (Castillo, 2021, p. 100)

Por otro lado, Delgado (2011), situado ahora desde las ciencias sociales y la educación popular, aborda el cruce entre acción colectiva y conocimiento emancipatorio. Para esto retoma algunos aportes de De Sousa (2006) para contribuir a una sociología de las ausencias desde la que se entiendan las prácticas sociales como prácticas de conocimiento. En este sentido, las acciones colectivas se pueden interpretar y entender desde la generación de lenguajes y narrativas, así como de imaginarios inéditos de problemas y de soluciones (Delgado, 2011, p. 4) debido a que son entendidas como agencias de significación 
colectiva (Melucci, 1994 y Gamson, 1992, citados en Delgado, 2007). Por otra parte, las acciones colectivas pueden entenderse desde la construcción de solidaridad, que plantea como un saber que es generado y movilizado en el núcleo de la acción colectiva y que es inacabado. Además, el autor menciona una construcción de nuevas territorialidades y temporalidades nacidas desde las lógicas locales y situadas donde se producen las acciones colectivas.

Por su parte, Barragán y Torres (2018) presentan un balance de la trayectoria del grupo de investigación al que pertenecen..$^{12}$ En este valioso documento, se desglosan las vertientes históricas que confluyen en los aportes conceptuales y metodológicos con los que han venido trabajando y en su diálogo estrecho con las organizaciones sociales. Resulta de particular interés la manera en que se fueron desligando del uso inductivo de conceptualizaciones heredadas de la escuela europea, para conocer cómo emergen y perduran los procesos organizativos, la identidad organizacional, la construcción de tejido social, los vínculos comunitarios y el tejido asociativo, los procesos formativos y pedagógicos, las subjetividades sociales y los nuevos sentidos políticos que agencian estas experiencias asociativas (Barragán y Torres, 2018, p. 17-18). Los rasgos que las caracterizan y a su vez constituyen sus dimensiones de análisis son:

- La existencia de elementos estructurales del contexto y conflictos que generan una dinámica asociativa.

- Los diversos tipos de actores y posiciones.

- Los cambios sociales que generan, aunque no sean siempre concebidos como revolucionarios.

- Las campañas, agendas y programas.

- Los repertorios de protesta.

- Las redes y formas de organización y comunicación.

- Las temporalidades de la lucha (incubación, consolidación, institucionalización).

- La formación de identidad colectiva.

- Los cambios en la cultura política.

Estas han sido algunas de las dimensiones que la espectrónica incorporó en su propuesta, en sintonía con la matriz de conocimientos situados en Latinoamérica y desde los mismos procesos sociales. Es importante reconocer que este tiempo de paro en Cali iniciado el 28 de abril, ha obedecido a un levantamiento popular, pero que lo popular, así como la categoría de pueblo, merecen la pena ser sopesados y reconocer de qué están hechos. Que no es una sola cosa definitiva ni se trata de un solo tipo de acción colectiva cuya expresión más visible es la "acción colectiva contenciosa" que constituyen los

12 Sujetos y nuevas narrativas en investigación y enseñanza de las ciencias sociales de la Universidad Pedagógica Nacional de Bogotá. 
bloqueos. En este caso, nos enfrentamos a una cantidad de iniciativas que se dan en dichos espacios, a su alrededor, pero también que suceden de forma desterritorializada (acciones colectivas comunicativas, por ejemplo), en suma, se trata de entramados instituyentes.

Uno de los retos que supone enfocarse en la dimensión educativa y de subjetividades emancipadoras es la manera en que se gestiona el conocimiento derivado de las mismas experiencias. En ese sentido, la sistematización de experiencias es una de esas apuestas metodológicas clave para asumir los retos de comprender la complejidad del subsuelo. A continuación, abordaré las particularidades de una apuesta como la espectrónica. Entre abril y junio de 2021, las dinámicas asociativas emergentes han tenido que ver con la comunicación, el feminismo, el ambientalismo, el arte, la pedagogía, el alimento, la salud comunitaria, lo recreativo, lo deportivo, entre otras.

\section{La espectrónica: una apuesta metodológica para analizar y potenciar acciones colectivas}

La espectrónica es una experiencia de sistematización de acciones colectivas nacida en Cali en el año 2011, y a su vez es fruto de una dinámica asociativa en un tiempo de muchas preguntas y necesidades. Unos amigos que hacían parte de un colectivo de comun \{icación alternativa, ${ }^{13}$ se inquietaron acerca de la potencia de ciertos eventos en el espacio público que, bajo coyunturas específicas y con demandas concretas, lograban convocar a varias colectividades y sujetos. Las dinámicas colaborativas de organización de dichos encuentros, el tipo de reivindicaciones planteadas, y los roles y las modalidades de acción resultaban muy significativos. Luego, estas iniciativas con el tiempo desaparecían, dejando el recuerdo de haber sido muy potentes.

Movidos por el deseo de entender las fuerzas colectivas que nutrían esos eventos y también de potenciar nuevos encuentros, las conversaciones e intercambios se fueron colmando de preguntas y posibles ejercicios a realizar, y poco a poco fue tomando forma un proyecto de investigación alimentado por algunas metodologías participativas con las que trabajaban, como la cartografía social y la poligrafía social. Se trató, en su primera fase, de un ejercicio de levantamiento y reconstrucción de aquellas acciones para caracterizar sus elementos constitutivos, analizarlos y percibir posibles continuidades. Este proyecto fue bautizado por uno de ellos como "la espectrónica", aludiendo a la expansión del espectro de estas movilizaciones y dinámicas asociativas. ${ }^{14}$ En su inicio se definieron unas dimensiones de análisis que comprendían la

13 La autora y su colega y buen amigo se conocieron mientras formaban parte de un colectivo de comunicación alternativa llamado La Direkta.

14 El nombre hace referencia tanto al espectro que se genera por las vibraciones parecidas o en la misma frecuencia, pero también a aquellas huellas que deja la asociación temporal, los ecos que permiten rastrear lo vivido. 
identificación de: necesidades o reivindicaciones, actores y repertorios de acción.

Años más tarde, la autora ingresa a una maestría en educación popular, y poco a poco sus intereses en metodologías participativas la llevan a volver a aquellos pasos investigativos de la espectrónica. Así que, durante ese periodo académico, esta iniciativa se analizó a la luz de una sistematización de experiencias. Una de sus grandes características fue haber nacido como una necesidad del mismo tejido asociativo; un modo particular, intuitivo y curioso de mapear las rizomáticas conexiones invisibles de un entramado que se urde en la cotidianidad. En este sentido, se acerca a un ejercicio profético, en tanto trabajo de lectura de señales desde la atención y la curiosidad epistemológica (Freire, 2012). Cabe aclarar que el interés no se centró en la discusión teórica acerca de la naturaleza de las acciones colectivas, se entendió como una fuerza instituyente cuyas dinámicas y fuerzas podrían ser legibles a través de un ejercicio como la espectrónica.

Estainiciativafue analizadabajo elmodelo desistematización de experiencias con el que ha venido trabajando el Grupo de Investigación en Educación Popular de la Universidad del Valle. Este modelo se concibe desde tres fases que no son secuenciales, sino que más bien se solapan y alimentan constantemente. Zúñiga y Gómez (2006) dan cuenta de estas tres fases. La primera es la fase de reconstrucción en la que se identifica una temporalidad a sistematizar, se activa una Unidad Hermenéutica (archivo de material tanto físico como digital en el que está condensada que contiene la memoria de la experiencia) y se levanta una cronología endógena. De esta fase resulta la elaboración de un macrorrelato que puede ser desde una crónica, un cómic o un mapa parlante. En la fase de interpretación se decanta lo hallado en la fase de reconstrucción resaltando aspectos o dimensiones significativas de la experiencia (núcleos temáticos). También se identifican diversas posturas y formas de percibir la experiencia identificando entramados de significación. Por último, la fase de potenciación ocurre todo el tiempo y obedece a la manera en que se vuelve a la experiencia después de haberla "leído" de varias formas. Se sintoniza con la expresión freiriana (2006) de "ser más" no en un nivel cuantitativo, sino cualitativo y resuena con las apuestas por construir conocimientos emancipatorios.

La espectrónica se nutrió de este modelo y además a su vez le hizo unos aportes. En primer lugar, en la fase de reconstrucción, propone un levantamiento de las acciones colectivas desde las dimensiones planteadas por Barragán y Torres (2018) en un cuadro o matriz. Para efectos de aclarar cómo podría emplearse esta matriz, se propone la siguiente tabla. 
Tabla 1. Matriz de espectro de acción colectiva

\begin{tabular}{|c|c|c|c|}
\hline \multirow{2}{*}{\begin{tabular}{|c|}
$\begin{array}{c}\text { Variables/dimensiones } \\
\text { de análisis }\end{array}$ \\
Fecha
\end{tabular}} & \multirow{2}{*}{\begin{tabular}{|c|} 
Explicación \\
puede ser la fecha específica o usar los códigos \# \\
$21 \mathrm{~A}$
\end{tabular}} & \multicolumn{2}{|c|}{ Espectro de acción colectiva } \\
\hline & & $23 \mathrm{~A}$ & $24 \mathrm{~A}$ \\
\hline Lugar & $\begin{array}{l}\text { Puede ser un punto de resistencia, una calle, un } \\
\text { referente. Si se trata de una marcha, se puede } \\
\text { mencionar el recorrido }\end{array}$ & $\ldots$ & $\ldots$ \\
\hline Evento & $\begin{array}{l}\text { En el marco del paro, puede tratarse de una } \\
\text { jornada especifica, }\end{array}$ & $\ldots$ & $\cdots$ \\
\hline actores y roles & $\begin{array}{c}\text { no se trata de una categoría analítica, puede } \\
\text { referirse a sujetos (primera línea, brigadistas de } \\
\text { salud, cocineras/os de las ollas, ) } \\
\end{array}$ & $\ldots$ & $\ldots$ \\
\hline Reivindicaciones & \begin{tabular}{|l|} 
El Paro logró definir ciertas reivindicaciones \\
comunes, pero se han ido presentando múltiples \\
banderas que orientan los marcos de acción.
\end{tabular} & $\ldots$ & $\cdots$ \\
\hline Repertorios & $\begin{array}{l}\text { bloqueo, barricada, marchas, plantones, pero } \\
\text { también tomas culturales, juegos, ollas } \\
\text { comunitarias, velatones, etc. }\end{array}$ & ... & $\ldots$ \\
\hline Redes de comunicación & $\begin{array}{c}\text { Redes de whatsapp, telegram y signal, tendencias } \\
\text { en twitter, facebook, y campañas de denuncia y } \\
\text { visibilización de la protesta en tiempo real }\end{array}$ & $\ldots$ & $\cdots$ \\
\hline $\begin{array}{l}\text { Construcción de } \\
\text { identidad }\end{array}$ & Se refiere a la manera de nombrar un nosotros & $\ldots$ & $\cdots$ \\
\hline Violaciones a DDHH & $\begin{array}{l}\text { Aquí se pueden incluir el reporte de violaciones a } \\
\text { DDHH y el seguimiento de las mismas }\end{array}$ & $\cdots$ & $\ldots$ \\
\hline $\begin{array}{c}\text { Solidaridad y redes de } \\
\text { apoyo }\end{array}$ & $\begin{array}{l}\text { Se puede tener en cuenta las redes locales } \\
\text { (apoyos de otros sectores sociales), nacionales e } \\
\text { internacionales }\end{array}$ & $\cdots$ & $\cdots$ \\
\hline Atmósfera afectiva & $\begin{array}{l}\text { En esta dimensión se puede incluir todo lo que se } \\
\text { experimente en lugares y a raiz del uso de ciertos } \\
\text { repertorios o el registro del abuso policial, por }\end{array}$ & $\ldots$ & $\cdots$ \\
\hline + Dimensión & $\ldots$ & $\ldots$ & $\ldots$ \\
\hline
\end{tabular}

Elaboración propia a partir de las dimensiones de Barragán y Torres (2018)

Nota: La tabla se diligencia según las necesidades y contexto de los participantes, y podría incluir las variables desde el enfoque interpretativo de las acciones colectivas que más se ajuste al contexto de sistematización.

Tal como se muestra en la tabla, en su eje horizontal se pueden incluir la cantidad de acciones, situaciones o eventos que se quieran mapear o reconstruir. Por ejemplo, delimitar una temporalidad entre finales de abril y finales de junio de 2021. En el eje vertical se podrán desglosar la cantidad y pertinencia de variables que se quieran analizar, teniendo en cuenta que se podría incluir o eliminar variables toda vez que se requiera.

Entonces, contamos con un instrumento de notación colectiva que permite reconstruir una experiencia de una o varias acciones colectivas, como un documento siempre abierto sobre el cual se pueden incluir tantas dimensiones como sean necesarias, así como reescrituras que expresan tensiones y desacuerdos. A este material resultante se le pueden hacer múltiples lecturas transversales y codificar por colores las tendencias para percibir las continuidades de un mismo proceso.

Una segunda pista que la espectrónica puede brindar a las experiencias que deseen sistematizar su accionar colectivo, tiene que ver con la fase de 
interpretación. En esta fase las lecturas transversales que contrastan la multiplicidad de perspectivas, pueden ser condensadas a partir de la elaboración de metáforas que pueden surgir de las mismas conversaciones, desde el potencial generador de la palabra (Freire, 2002), también se pueden decantar de la matriz de acciones colectivas de la fase de reconstrucción. Estas metáforas pueden aglutinar la complejidad de significaciones y dimensiones sociales que escapan a las palabras y resultan formas narrativas inéditas capaces de devolver la mirada sobre las propias experiencias, reconociendo e intuyendo los aspectos más relevantes.

Las pistas que ofrece la espectrónica orbitan alrededor de las posibilidades de leer desde abajo, en consonancia con los ritmos y necesidades de los mismos procesos, las dimensiones que las constituyen. Se trata de una propuesta para la gestión colectiva del conocimiento que puede resultar muy útil para decantar y potenciar el conocimiento emancipatorio del periodo de efervescencia de la protesta social en los últimos tiempos.

\section{A manera de cierre: entre el horror y la esperanza}

Uno de los aspectos más relevantes de pensar en clave de acciones colectivas para asir la complejidad del presente denso que ha sido este tiempo en el paro nacional, es la capacidad de reconocer las fuerzas instituyentes como las que se han venido presentando, que no parecen asentarse pero que anuncian importantes procesos y dinámicas de transformación social. En los discursos oficiales estas fuerzas son leídas como brotes infiltrados por una izquierda brumosa, lo suficientemente ambigua y monstruosa que ha venido calando en el imaginario de la protesta social, a la par que aumenta la represión policial de la misma. En este escenario se configuran las lógicas de necropolítica y silenciamiento que buscan, a través del miedo, neutralizar los brotes en ciernes.

Este tipo de apuesta considera la continuidad y transformación de procesos emancipatorios leída desde la educación popular que a través de múltiples escenarios, formales y no formales, y en sintonía con las dimensiones subjetivas, afectivas y vinculares, busca contribuir a nutrir la gestión colectiva del conocimiento situado. Es decir, el aprendizaje desde las mismas experiencias. La espectrónica puede entenderse entonces como una herramienta contrahegemónica porque uno de los elementos que configura la represión es la desintegración de las narrativas que nos permiten tejer las continuidades y rupturas de la protesta social en la región y el país. Esto sucede a través de la estigmatización y criminalización de la protesta, y también a partir de la fabricación de discursos explicativos de la emergencia social ${ }^{15}$ que a través de los medios masivos y redes sociales, y apelando a la dimensión afectiva, logran calar afectivamente en un segmento de la sociedad.

15 Como fue el caso de la Revolución Molecular Disipada Recuperado de https://cerosetenta.uniandes.edu. co/revolucion-molecular-disipada-y-otros-monstruos-debajo-de-la-cama/ 
Las pistas que ofrece la espectrónica invitan a quienes se juntan a realizar distintos tipos de acción colectiva a percibir en esos brotes las particularidades asociativas que posibilitan una relación distinta con una ciudad que ha fabricado por años una exclusión y que hoy se expresan en la superficie con gran riqueza de modalidades y repertorios de acción. Esta herramienta se propone leer las fuerzas asociativas cobijadas bajo la coyuntura del paro nacional intentando dialogar con los aportes conceptuales que se hagan en términos de su comprensión. Por eso se nutre de algunas características interpretativas de la acción colectiva que pueden ser apropiadas de acuerdo a las necesidades emergentes. El paro nacional continúa, y con él las lógicas de muerte y de resistencia. De quienes participamos en este proceso depende cómo podemos reescribir tanto la historia como el presente denso.

\section{Referencias bibliográficas}

Arciniegas, G. (1939). Los comuneros (N. 918.8 Ar26). ABC.

Barragán Cordero, D. y Torres Carillo, A. (2018). Producir conocimiento desde la acción colectiva. Colección CIUP 41 años.

De Sousa Santos, B. (2006). Renovar la teoría crítica y reinventar la emancipación social. Buenos Aires: Clacso.

Castillo, L. C. (2021). Arde Cali, sucursal del cielo y capital mundial de la salsa. En Pensar la Resistencia. Mayo del 2021 en Cali y Colombia. Documentos especiales CIDSE N. 6. Universidad del Valle.

Castro, L. (2018). La acción colectiva feminista, ¿de la lucha de clases a la lucha de géneros? Aportes para la comprensión práctica de los movimientos sociales: el caso "Ni Una Menos". Ciencia Política, 13(26), 19-61.

Rodríguez, E. C. (2015). El derecho a la protesta social en Colombia. Pensamiento jurídico, (42), 47-69.

Cruz, E. (2016). El ciclo de protesta 2010-2016 en Colombia. Una explicación. Jurídicas CUC, 12(1), 31-62. DOI: http://dx.doi.org/10.17981/juridcuc.12.1.2016.3

Delgado, R. (2011). Acción colectiva y educación popular: contribuciones para un conocimiento emancipatorio. Folios, (33), 53-6o.

Díaz, H. H. (2021). Comentarios para una historia crítica del presente: el paro nacional de abril de 2021 en Colombia como acontecimiento. Cambios y Permanencias, 12(1), 619-645.

El Espectador. Estado asesino y otros graffitis que han sido borrados. https://www.elespectador.com/judicial/mural-estado-asesino-y-otros-graffitis-que-han-sido-borrados-article/

Freire, P. (2002). Pedagogía del oprimido. Buenos Aires: Siglo XXI.

Freire, P. (1996). Cartas a Cristina. Ciudad de México: Siglo XXI.

Freire, P. (2012). Pedagogía de la indignación: cartas pedagógicas en un mundo revuelto. Buenos Aires: Siglo XXI.

Garcés, M. (2020). Escuela de aprendices. Barcelona: Galaxia Gutenberg.

García, M. (2017) . 40 años del Paro Cívico Nacional de 1977. Revista Cien Días, 91, 19-24.

Guzmán, José Luis. El País. Recuperado de https://www.elpais.com.co/cali/polemica-por-derribo-de-la-estatua-de-sebastian-de-belalcazar-que-hay-detras-de-lo-ocurrido-en.html

Hernández, J. (2021). De la marcha hacia el centro al bloqueo en los barrios: Las luchas por reconocimiento y oportunidades en Cali durante el paro nacional de abril-mayo de 
2021. En Pensar la resistencia. Mayo del 2021 en Cali y Colombia. Documentos especiales CIDSE N. 6. Universidad del Valle.

Indepaz. (2021). Registros del observatorio de conflictividades y DDHH de Indepaz.

Recuperado de http://www.indepaz.org.co/wp-content/uploads/2021/04/CON-LI\%CC\%81DERES-HAY-PAZ.pdf

Márquez, F. (2020). Por una antropología de los escombros. El estallido social en Plaza Dignidad, Santiago de Chile. Revista 180, (45), 1-13.

Mbembe, A. (2020). Necropolítica. Melusina.

Melucci, A. (1999). Acción colectiva, vida cotidiana y democracia. Ciudad de México: El Colegio de México.

Libreros, D. (2021). A propósito del levantamiento popular del 28 de abril. Revista Izquierda (99) 5-17.

Pazos-Cárdenas, M. (2021). Necropolítica y capitalismo gore en la región del Pacífico sur colombiano. Sociedad y Economía, (42).

Quintana, L. (2020). Política de los cuerpos: Emancipaciones desde y más allá de Jacques Rancière. Ciudad de México: Herder.

Segato, R. (2018). Contra-pedagogías de la crueldad. Buenos Aires: Prometeo editorial.

Tapia, L. (2001). Política salvaje. Buenos Aires: Clacso.

Tilly, C. (1998). Conflicto político y cambio social. In Los movimientos sociales: transformaciones políticas y cambio cultural (p. 25-42). Madrid: Trotta.

Torres, A. (2011). Educación popular: trayectoria y actualidad. Caracas: Universidad Bolivariana de Venezuela.

Touraine, A. (1997) • ¿Podremos vivir juntos? Ciudad de México: Fondo de Cultura Económica.

Zúñiga Escobar, M. y Gómez Zúñiga, R. (2006). Mujeres Paz-íficas de Cali: La paz escrita en cuerpo de mujer. Cali: Programa Editorial UNIVALLE. 
